\title{
RF Optimization of GSM Networks Using Antenna Parameters
}

\author{
Y.V.S Durga Prasad, ${ }^{2}$ M.Usha Rani, 3 Dr.V.S.S.N.Srinivas Baba \\ ${ }^{1}$ Associate Professor, ECE Dept, ACE Engineering college,Hyderabad,Prasadece.304@gmail.com \\ ${ }^{2}$ Assistant Professor, ECE Dept, ACE Engineering College, Hyderabad, usha.rani1991@gmail.com \\ 3 Professor, ECE Dept, ACE Engineering College, Hyderabad, vssnsbaba@gmail.com
}

\begin{abstract}
GSM network operators use Key Performance Indicators (KPIs) to evaluate their network performance and the Quality of Service (QoS) with reference to end user perspective. In the present work, optimization of GSM network is analyzed using drive test results. Network optimization process is introduced and then network optimization using antenna parameter setting is analyzed, finally the impact of incorrect antenna parameter setting on network optimization is illustrated. GSM network RF performance evaluation is presented based on some major KPIs such as Call set up success rate (CSSR), Call Drop Rate (CDR), Handover Success Rate (HSR) and Traffic channel (TCH) congestion rate.
\end{abstract}

Key words: RF Optimization, GSM Network, KPIs, Antenna Parameters

\section{I.INTRODUCTION}

The present optimization methods always use measured data to analyze network performance and do not directly consider the disturbance intensity which is directly related to the distance, azimuth, relative position, and other factors. During the measuring period, many problems may occur such as in sufficient bins( sampling points), base station failure or other problems caused by accidental factors. These problems affect the measured data accuracy and the same or adjacent channel frequency allocation results. Co channel and Adjacent channel interference generated affects the network performance[1]. Therefore, factors such as Distance, Azimuth and Relative position of the network should be considered for channel interference verification and Optimization

\section{OPTIMIZATION-METHODOLOGY}

Optimization is a process of identification and rectification of performance affecting problems within the constraints of an existing network infrastructure. Optimization of the radio network consists of two phases. In first phase- single site optimization is done and in second phase - Cluster optimization is taken up. In Single site optimization, each and every site is verified for their KPI performance. This is known as Single Site Verification (SSV). Later according to the problem faced by the site, it is optimized physically and parameter wise. In cluster optimization, entire cluster will be verified and the results will be obtained. This is known as pre drive. Based up on KPI result Analysis, recommendations such as antenna orientations are given[4]. After implementing the recommended changes, the entire cluster's performance is verified again and results are compared with the pre-drive to observe whether required KPI'S as prescribed by TRAI are met. This is known as Post Drive. The same process is extended to entire network for performance improval.

2.1 Network performance metrics taken into consideration:

2.1.1. Idle Mode: The purpose of Idle mode is just to verify the coverage area in a cell site. Receiver ( $\mathrm{Rx})$ level up to $-85 \mathrm{dBm}$ is considered to be acceptable. No call is initiated from the mobile phone in this mode.

2.1.2. Dedicated Mode: The purpose of this mode is to verify all the parameters like Call setup, Call success, Handover failure, Call drop etc. In this mode mobile is operated in two call modes. One is short call mode and the other is long call mode. The purpose of the short call is used to know the Call Accessibility and the purpose of the long call is to know about Call Retainability. In short call, important parameters like Blocked calls, Dropped calls, Call attempts, Call success are mainly observed. In long call parameters like Handover failures[2], Handover success rate are observed

2.2. Algorithm for Optimization:

All these individual sites are present in the cluster and then one can verify whether handover is performed from one site to another site. All the parameters like Antenna Height, Azimuth angle. Antenna Down tilt (Electrical), Antenna down tilt (Mechanical), Expected coverage areas etc. are be observed while evaluating the network

2.3. Single Site Verification (SSV):

In single Site Verification, physical and network parameters of the single site are verified. Based on the performance of the site, certain changes in both physical level as well as parameter level of the site are recommended. Physical parameters like Antenna Orientation, Tilt, Height and SWAP etc. are observed for their variation from the values given in the database of the site during its RF survey process

2.4 Experimental Procedure

In this experimental work, a group of cell sites identified as AP_Hyder_xxx, AP_Hyder_yyy, AP_Hyder_zzz,AP_Hyder_ppp, AP_Hyder_qqq are taken as a cluster and SSV for each and individual cell sites was performed and physical and parameter verification using a drive test kit[3]. The procedure for the SSV drive test is performed in three types of call scenarios as i) Mobile Station1 = Idle ii) Mobile Station $2=$ Short call (MS to MSC Test Number, $45 \mathrm{sec}$ call duration, 10 sec call interval) iii) Mobile Station $3=$ Long call (MS to 
MSC Test Number, 10 sec call interval if call drops) The results of individual SSV are presented in figure 2 and 3.

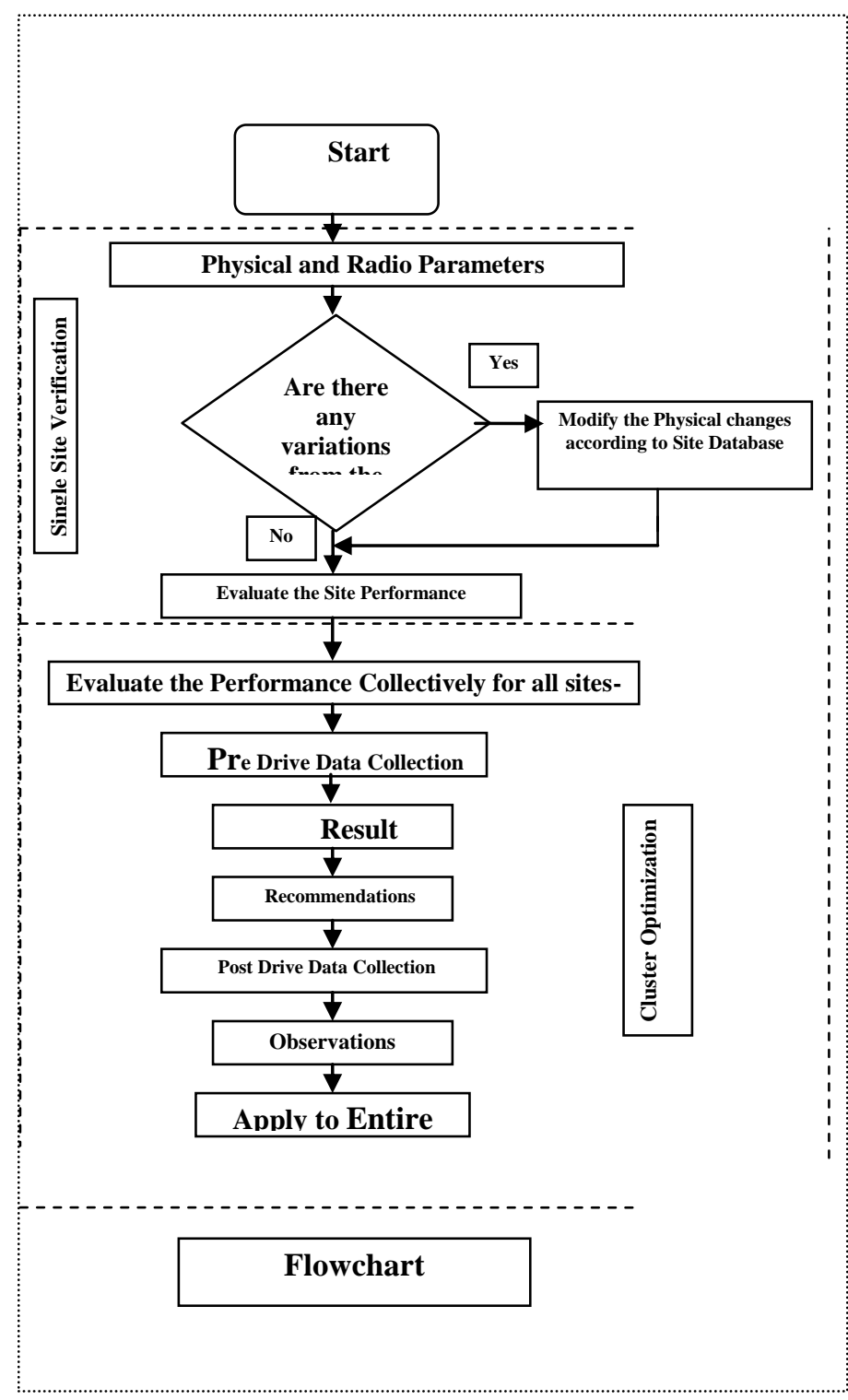

FIG 1: ALGORITHM FOR OPTIMIZATION

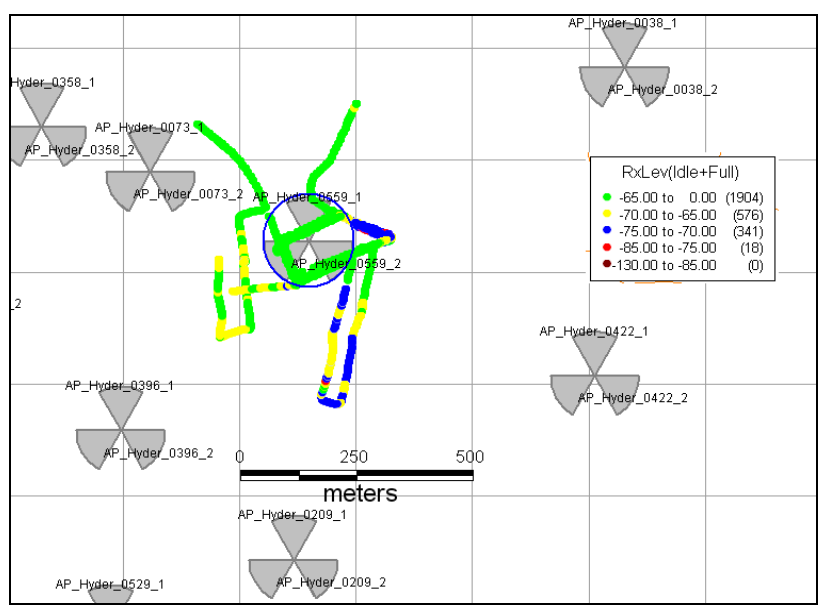

figure 2: Signal Strength Map - GSM (Rx Level - Idle mode

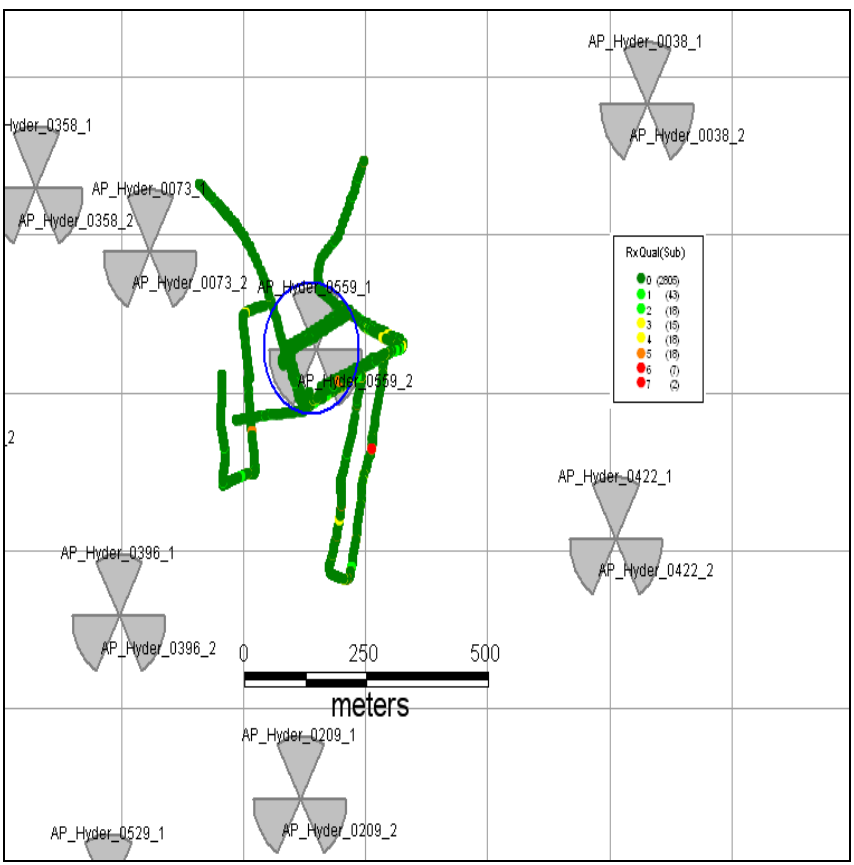

Fig 3: Rx Quality Map - GSM (Rx_Qual -Long call)

\section{RESULTS AND DISCUSSION}

The SSV and Cluster Drive Test the results of the Rx_Level and Rx_Qual for the individual site

are presented in figure 1 and figure 2 . From these results Rx level and quality of the particular site is observed. Also handover are performed from one sector to another sector in clock-wise, anti clock-wise directions and along the sector to ensure Retainability are observed.

SITE 5:AP_HYDER_0559 Site information:

\begin{tabular}{|c|c|c|c|c|c|c|}
\hline \multicolumn{3}{|c|}{ Pre Configuration } & \multirow{2}{*}{$\begin{array}{l}\text { Antenna } \\
\text { paramete } \\
\text { r }\end{array}$} & \multicolumn{3}{|c|}{$\begin{array}{l}\text { Post/Audited } \\
\text { Configuration }\end{array}$} \\
\hline $\begin{array}{l}\text { Sect } \\
\text { or } 1\end{array}$ & $\begin{array}{l}\text { Sect } \\
\text { or } 2\end{array}$ & $\begin{array}{l}\text { Sect } \\
\text { or } 3\end{array}$ & & $\begin{array}{c}\text { Sec } \\
\text { tor } \\
1\end{array}$ & $\begin{array}{l}\text { Sect } \\
\text { or } 2\end{array}$ & $\begin{array}{l}\text { Sect } \\
\text { or } 3\end{array}$ \\
\hline 26 & 26 & 26 & $\begin{array}{c}\text { Antenna } \\
\text { Height } \\
\text { (mtrs) } \\
\text { AGL }\end{array}$ & 26 & 26 & 26 \\
\hline 0 & 120 & 210 & Azimuth & 0 & 120 & 240 \\
\hline 2 & 2 & 2 & $\begin{array}{c}\text { Antenna } \\
\text { down tilt } \\
\text { (Electric } \\
\text { al) }\end{array}$ & 2 & 2 & 2 \\
\hline 0 & 0 & 0 & $\begin{array}{c}\text { Antenna } \\
\text { down tilt } \\
\text { (Mechani } \\
\text { cal) }\end{array}$ & 1 & 1 & 1 \\
\hline
\end{tabular}

Table 2 : Antenna parameters Pre \& Post Configuration 


\begin{tabular}{|c|c|c|c|}
\hline Name & Sector-1 & Sector-2 & Sector-3 \\
\hline Rx Quality & 0 & 0 & 0 \\
\hline $\begin{array}{c}\text { RX Level (Near Site) } \\
d B m\end{array}$ & -45 & -49 & -47 \\
\hline
\end{tabular}

Table 3: Site 5 check sheet

All these individual sites are present in the cluster are verified to find out whether handover is performed from one site to another site or not. All the parameters like Antenna Height, Azimuth angle. Antenna Down tilt (Electrical), Antenna down angle. Antenna Down tilt (Electrical), Antenna down tilt (Mechanical), expected coverage areas etc. were observed. In the second phase of optimization a pre optimization cluster drive had been carried out in order to know the performance of the whole cluster. Based on the KPIs observed in the pre drive some recommendations were given and the same had been implemented in the cluster. A post drive had been carried out and respective plots of various parameters were observed and presented as follows.

angle. Antenna Down tilt (Electrical), Antenna down tilt (Mechanical), expected coverage areas etc. were observed. In the second phase of optimization a pre optimization cluster drive had been carried out in order to know the performance of the whole cluster. Based on the KPIs observed in the pre drive some recommendations were given and the same had been implemented in the cluster[5]. A post drive had been carried out and respective plots of various parameters were observed and presented as follows.

\begin{tabular}{|c|c|c|}
\hline Range $(\mathrm{dBm})$ & $\begin{array}{c}\text { Pre - Drive } \\
\text { Cluster }\end{array}$ & $\begin{array}{c}\text { Post- } \\
\text { Drive } \\
\text { Cluster }\end{array}$ \\
\hline 0 to -65 & $80.52 \%$ & $84.16 \%$ \\
\hline-65 to -70 & $11.08 \%$ & $11.68 \%$ \\
\hline-70 to -75 & $4.40 \%$ & $3.72 \%$ \\
\hline-75 to -85 & $3.95 \%$ & $0.43 \%$ \\
\hline-85 to -130 & $0.02 \%$ & $0 \%$ \\
\hline TOTAL & $100 \%$ & $100 \%$ \\
\hline
\end{tabular}

Table 4: Percentage of Rx_Level in Pre-Drive Cluster \& Post Drive Clusters

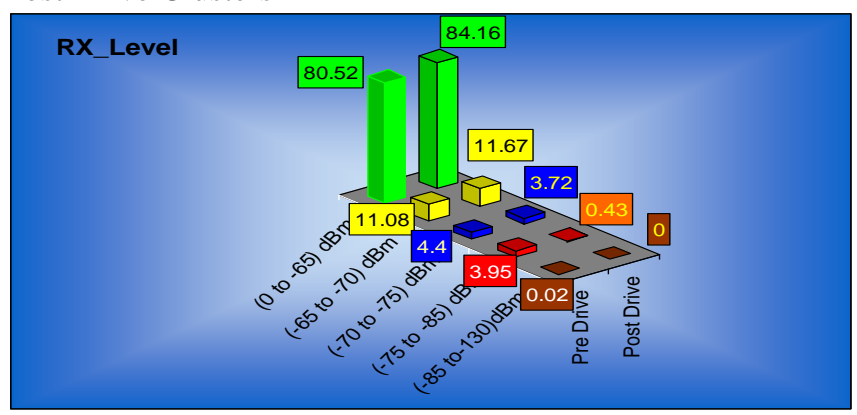

Fig:4: Bar graph of Percentage of Rx_Level in Pre-Drive Cluster \& Post Drive Clusters
From above table it can be observed that percentage of RX-Signal in Post Cluster after implementation of recommended changes (84.5\%) is improved $4.5 \%$ than in Pre cluster Drive $(80 \%)$ in desired Rx-Level 0 to $-65 \mathrm{~dB}$ and also there is no RX-Level after $-85 \mathrm{~dB}$ as per recommendations of TRAI

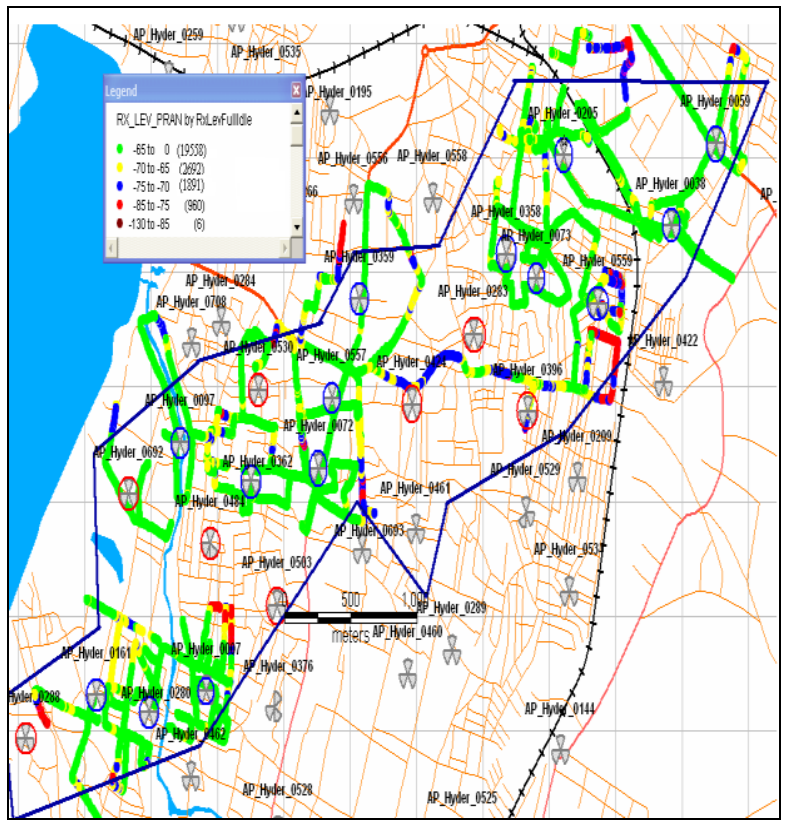

Fig 5 :Rx Level: Pre-Cluster Drive:

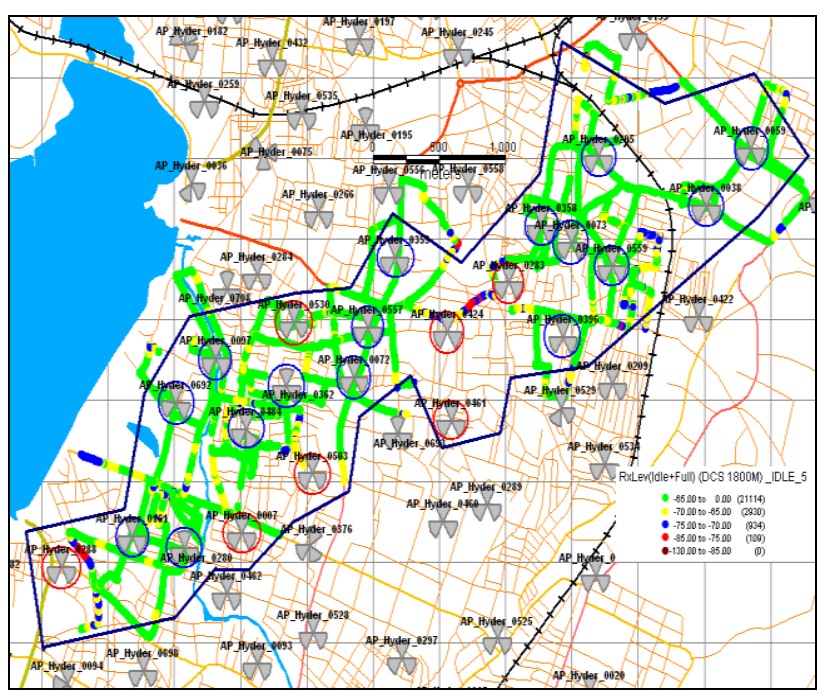

Fig 6 :Rx Level: Post-Cluster Drive: REFERENCES

[1] Sharma.A, Konai.S, Bhattacharya - New Call and handoff call management scheme for reuse partitioning based cellular systems, IEEE, 9-11 May 2014, Pg 1-7

[2] Rf Optimization For Quality Improvement In Gsm Network, Ijeet Volume 6, Issue 8, Sep-Oct, 2015, pp.53-62

[3] Sh. Seytnazarov,"RF optimization issues in GSM networks", IAICT 4th international conference paper, 12-14 Oct. 2010.

[4] . Radio Frequency Optimization \& QoS Evaluation in Operational GSM Network Proceedings of the World Congress on Engineering and Computer Science 2009 Vol I WCECS 2009, October 20-22, 2009, San Francisco, USA

[5] A Practical Approach of Planning and Optimization for Efficient Usage of GSM Network. International Journal of Communications (IJC) Volume 1 Issue 1, December 2012. 